\title{
Association of temporal factors and suicides in the United States, 2000-2004
}

\author{
Augustine J. Kposowa $\cdot$ Stephanie D’Auria
}

Received: 10 August 2008/Accepted: 3 June 2009/Published online: 18 June 2009

(c) The Author(s) 2009. This article is published with open access at Springerlink.com

\begin{abstract}
Objective The purpose of the study was to examine the association of temporal factors, in particular days of the week and seasons of the year and death from suicide in the United States.

Method Data were pooled from the Multiple Cause of Death Files. Hierarchical logistic regression models were fitted to all deaths occurring in 2000 through 2004 by suicide.

Results The incidence of suicide was significantly higher on Wednesdays, compared to Sunday. Specifically, individuals were $99 \%$ more likely to kill themselves on Wednesday than on Sunday. Suicides were more prevalent in the summer months, and they were less likely to occur in winter. The state suicide rate significantly elevated individual suicide risk. The results held even after controlling for the potentially confounding effects of socio-economic and demographic variables at both the individual and state levels.

Conclusion It was concluded that the observed association between seasonality and suicide cannot be discounted as a mere coincidence. Future research ought to focus on integrating individual level data and contextual variables when testing for seasonality effects.
\end{abstract}

Keywords Suicides - Seasonality - Daily variations . State suicide rate $\cdot$ Multi-level models

\footnotetext{
A. J. Kposowa $(\bowtie) \cdot$ S. D’Auria

Department of Sociology, University of California,

1150 Watkins Hall, Riverside, CA 92521, USA

e-mail: augustine.kposowa@ucr.edu; ajkposowa@sbcglobal.net

S. D'Auria

e-mail: sdaur001@student.ucr.edu
}

\section{Introduction}

Attempts to link the natural environment, especially temporal characteristics to suicide have a long tradition in the biomedical and social sciences. Some analysts report that seasons influence affective disorders [19]. Others indicate that cold and long winter nights increase suicide rates [78]. In many cultures, there is a popular belief that the weather, seasons, and even lunar cycles may be associated with suicide. As far back as 1842, Quetelet [64, p. 90] made a case for a possible effect of the natural environment on humans, pointing out that "the seasons in their course, exact a marked influence" on human behavior.

Among earlier quantitative efforts to provide empirical evidence in support of the impact of seasonality on suicide was the work of Morselli [55]. He compiled suicide and climatic data on 28 European countries in the late nineteenth century and observed that the seasonal regularity in annual suicide statistics was "too great for it to be attributed to chance of the human will" (p. 120). Morselli [55] indicated that the temperate part of Europe provided the most favorable environment for suicide and that most suicides took place during summer, with the fewest taking place in winter. He was among the first to point out that mood disorders could be influenced by the weather, concluding, for example, that temperature increased suicide risk by interfering with brain functions.

In his book Suicide, Durkheim [18] observed correlations between suicide and day of the week and month of the year, adding that these associations displayed certain similarities of form and origin. He generalized that suicide is higher in the first part of new periods (e.g., start of the week), and lower at the end of new periods (e.g., end of the week). In addition, Durkheim [18] found that most suicides occurred in the afternoon. In accounting for these findings, however, 
he discounted the role of climatic and temporal factors, indicating that "to explain it one could certainly not refer to the action of the sun and the temperature" (p. 117). He proposed instead that sociological variables mediated the relationship between the temporal associations and suicide. As he put it, the environmental explanation "...being discarded, we have but one other possible, namely, that day favors suicide because this is time of most active existence, when human relations cross and recross, when social life is most intense... Whatever information is available to us as to how suicide is distributed among the different hours of the day or the different days of the week confirms this view" ( $p$. 117). Durkheim also reported that most suicides occurred in the spring, not summer. To explain this observation, he once again downplayed the role of the natural environment, and went instead for a sociological explanation. According to him, most suicides took place in spring because "everything begins to awake; activity is resumed, relations spring up, interchanges increase." (p. 119). In other words, it is the density of human interactions, and not the environment that caused higher incidence of suicide in spring. Thus, although [18] examined the role of cosmic factors in the etiology of suicide, he moved away from attributing direct association with them. In his view, the natural environment had no direct bearing on the incidence of suicide, which he felt depended on social conditions and the intensity of human interactions, or what Massing and Angermeyer [51] have described as the varying intensity of social life. Thus, suicide was not a direct result of physical or climatic conditions.

More contemporary quantitative studies on the relationship between temporal variables and suicide, however, have produced a major puzzle. Some investigators have reported associations between seasonality and suicide [7, 10, 16, 34, 41, 46]. Lambert et al. [41] noted that the incidence of suicide in southeastern Australia shows a clear seasonal pattern. They found that suicides peak during spring and summer months, indicating a positive association between suicide incidents and prevailing sunlight levels. In contrast, Edwards and Whitlock [21] found a spring peak in the number of suicides committed in Brisbane, Australia, but the results were not statistically significant. Dublin [16] reported that the incidence of suicide varied according to seasons in the northern hemisphere, but contrary results were found for the southern hemisphere. Landau and Fridman [43, p. 164] affirmed that "Much of previous research on this topic has produced inconsistent and contradictory findings." For example, although Rotton [68] observed a significant relationship between winter months (December, January, and February) and suicide, the signs were in the negative direction, a finding that contradicts those reported by Barraclough [4], Gabennesch [22], and Kevan [33]. In a 2007 study of suicide counts in
England and Wales, Page et al. [59, p. 109] contradicted many prior findings of a spring or summer peak in suicide deaths, noting instead that most suicides occur in January (winter). A review of 27 quantitative studies by Deisenhammer [14] reported that much of the literature on seasonality and suicide is contradictory.

\section{Past research}

Most researchers who have identified an association between seasonality and suicide found a peak during the spring or summer [31, 60]. Petridou et al. [60] conducted a study that involved 20 countries and found an early summer peak. They concluded that the seasonal variation in suicide incidence could be explained by the increase in sunshine in summer months. A relationship between sunshine, high temperatures and suicide rate has since been supported by other studies as well [44, 59, 62]. Yet Deisenhammer's [14] review of the existing literature found that most studies failed to control for potentially confounding variables, a situation that seriously calls into question the validity of some claims. Further, adding to the controversy are findings with regard to sex differences in the seasonal distribution of suicides [5, 65]. Several investigators have found that the seasonal suicide incidence has one peak in spring for men and a bimodal peak, one in spring and one in autumn, for women [23, 53]. However, one peak in spring or summer, regardless of sex differences, has been found in the United States [45] and Taiwan [44].

At the cross-national level, researchers have found evidence in support of the influence of season, climate, month, and week on intentional violence. Kok [35] reported a strong relationship between climatic variables such as temperature, wind speed, rainfall and humidity and suicide in Singapore. Using regression analysis in France, Souetre et al. [73] noted that among all the variables analyzed, the main factors affecting the regional distribution of suicide were ambient temperature and sunlight duration.

In a study based on the US population, MacMahon [50] analyzed 129,621 US suicides recorded between 1972 and 1978. He found that in each year, suicides peaked in late spring and dropped in winter. In each month, suicides peaked on the fifth day and dropped until the end of the month. In terms of days, MacMahon [50] reported that suicides peaked on Monday and dropped to weekend lows. In a replication of the MacMahon [50] study, McCleary et al. [52] found support for the effects of days of the week, but no support was found for months on suicide rates in the United States. In the years following these studies, there has been relatively little research on the relationship between day of the week and suicide in the United States. 
In a West German study undertaken by Lamp [42] season of the year, especially summer had an impact on rape, theft, and other forms of violence, but not on suicide. Maldonado and Kraus [49] studied suicides committed in Sacramento County, California between 1925 and 1983 and found that the occurrence of suicide varied substantially by time of day, with the fewest taking place between 4:00 and 8:00 a.m. They reported, however, that suicides were most frequent on Monday, and this held true for both males and females, regardless of age. They observed no significant finding with regard to month or lunar phase. Maldonado and Kraus [49] also remarked that suicides occur at an almost equal frequency during the seasons.

Other works on the relationship between temporal factors and suicide have been done by Hassan [24] and Stack [74]. Hassan [24] used death registration data on 19,525 suicides recorded in Australia between 1981 and 1990 to study the impact of moon phase, day of the week, month of the year, and season. According to Hassan [24, p. 89], the highest incidence of suicide for both men and women was on Mondays, a finding consistent with those of Maldonado and Kraus [49]. With regard to seasons, however, Hassan contradicted findings by Maldonado and Kraus and affirmed that in Australia, suicides do vary according to seasons. For both men and women, the highest incidence of suicide in Australia tended to occur in the spring. With regard to lunar phases, Hassan [24, p. 89] observed "that except for the Full Moon Day, the average daily suicide in various lunar phases varies only slightly." He noted that the mean suicide for the Full Moon Day was higher than the daily mean in different lunar phases.

Stack [74] retested Gabennesch's argument that temporal factors affect suicide because of an unfavorable contrast between raised expectations and reality. According to Gabennesch [22] weekends, holidays, and new seasons raise expectations for a better mood. They also offer hope for a new and better beginning at the end of the holiday, week, or season. If these raised expectations are not fulfilled, the suicidal individual may feel deprived and depressed, and may subsequently destroy himself/herself [22]. In short, disappointments, resulting from unfulfilled expectations explain higher suicides on certain days (as opposed to others), and in certain months (as opposed to others). In re-testing the above ideas, Stack [74, p. 318] found that suicides peak in the spring months (March, April, and May).

Some scholars report that the seasonality of suicides has decreased or even vanished in recent years [58, 71, 80]. Oravecz et al. [58] compared data on suicides in Slovenia from 1983 to 1993 with suicides that occurred from 1994 to 1998 and found that the seasonal influence on suicide present prior to 1994 had disappeared. Yip et al. [80] studied the suicide incidence in England and Wales between 1982 and 1996 and found that although the seasonal variation in suicide rate present in England and Wales in the 1960s and 1970s had not vanished, it had greatly decreased. A recent multicentre study in England and Wales [26] observed temporal patterns of self-harm, with diurnal variations in time of presentation to hospital peaking between 10:00 p.m. and 2:00 a.m. That investigation was, however, limited to deliberate self-harm and did not include completed suicides. In addition, no effort was made by the authors to control for day of the week or season.

As the foregoing review has shown that several analysts have found either no relationship between temporal variables and suicide, or have reported conflicting findings [4, 33, 57, 59]. As Kevan [33, p. 368-369] remarks, "It must be pointed out to all those who are interested in man's seasonal behavior that there is little likelihood of finding any clear-cut relationship between atmospheric conditions and human behavior...Man's reactions are not going to be easy to understand, and so, there is no reason to expect an early resolution to the socio-economic/biometeorological debate on suicide."

The present study offers an opportunity to reexamine the association between temporal factors and suicide with the aim of resolving some of the inconsistencies in the existing literature. An added advantage of the present analysis over previous ones is the use of a nationally representative sample, and the entire universe of suicide deaths occurring in the United States. To increase statistical power, and to avoid drawing false inferences based on unexpected yearly fluctuations, we pool data for 5 years, 2000-2004. Finally, hierarchical models are specified.

The present study employs a multi-level approach to investigate the association of temporal factors and suicide risk. The response variable is suicide risk measured at the individual level. The predictor variables are measured at both level 1 (individual) and level 2 (US state). A number of research questions are addressed: (1) Are days of the week associated with suicide? (2) Are seasons of the year related to suicide? (3) Do states with high suicide rates influence individual suicide risk? (4) Do observed daily and seasonal patterns in suicide risk hold for Whites and Non-Whites? (5) What are the implications of answers to the above questions for past and future research?

\section{Analytical strategy}

In multi-level data with a categorical response variable, it is desirable to use a hierarchical generalized linear modeling technique that incorporates a unique random effect into the equation for each higher level observation. This 
approach produces more robust standard errors than those produced via techniques that do not allow nested models [66]. In contextual analysis, dependence may arise because individuals within a given level 2 unit for example, the state, have shared experiences and expectations. In short, persons within a state may have more in common with their state citizens than with individuals residing in other states. The situation is similar to 'design effect' issues that arise in complex surveys due to clustering of observations, and hence the need to obtain robust standard errors by applying appropriate variance estimation techniques. In multi-level models with binary outcomes, therefore, calculated standard errors must adjust for the variability in random effects [66]. In the present analysis, the GLIMMIX procedure in SAS 9.2 [69] was used to estimate parameters.

Hierarchical modeling approaches are rare in the suicide literature in general. A search of PUBMED (http://www. ncbi.nlm.nih.gov/) [61] and Sociological Abstracts (http:// www.csa.com) [72] covering the past 2 decades produced none that used the approach in the investigation of the link between temporal factors (seasonality) and suicide. Multilevel techniques have appeared only recently in suicide research, including that by van Tubergen et al. [77], and by Stack and Kposowa [75]. Van Tubergen et al. [77] examined completed suicides, while Stack and Kposowa [75] studied suicide acceptability at the cross-national level. The multi-level or mixed modeling approach recognizes the fact that most individual events do not occur in a vacuum, but are located in time and space. Thus, just as individual characteristics can have effects on the odds of suicide, contextual factors can also affect individual odds.

Past studies have reported that suicide attempters have generally had more contact with role models that have committed suicide [3]. As Stack and Kposowa [75, p. 41] observe, in communities with more persons that have died of suicide, there could be greater interaction with individuals that have attitudes favorable to suicide. This study recognizes the possibility of the complex relationship between macro structural factors and micro characteristics by modeling individuals as located in their states of residence, taking into account that some of the individual risk factors may be due to state differences.

\section{Methods}

\section{Data}

The data used in the study were derived from the national US Multiple Cause of Death Files (MCDFs) for 2000 2004 [56]. The MCDFs contain mortality statistics based on the information from death certificate records of all deaths occurring in the United States. The information is received on computer data tapes coded by the States and provided to the National Center for Health Statistics (NCHS), through the Vital Statistics Cooperative Program, or are coded by NCHS staff from copies of the original certificates received from registration areas. NCHS receives the data for the MCD Files from the registration offices of all States, the District of Columbia, and New York City. Mortality data for the United States are limited to deaths occurring within the country to US residents and nonresidents. Deaths occurring to US citizens outside the United States are not included in the MCDF [56]. A more detailed description of the MCDFs has been presented elsewhere [56].

The current analysis focused on suicide deaths among non-Hispanic whites, non-Hispanic African Americans, non-Hispanic Native Americans (American Indians), nonHispanic Asians, and Hispanics aged 18 years and above. The results presented are based on those adults 18 years old and above who died of suicide in their state of residence in the years 2000 (24,279), $2001(25,315), 2002$ $(28,944), 2003(26,202)$ and $2004(26,896)$.

\section{Dependent variable}

The MCDF is cross-sectional, and lacks population denominators. Therefore, a case-control design was employed in this study. The response variable was the odds of death by suicide (the cases), as opposed to deaths from natural causes (the controls). The data used do not permit a comparison of victims versus non-victims (those still alive), so the 'non-victims' in the analysis are those who died of natural causes. Deaths resulting from suicide were defined according to the Tenth Revision of the International Classification of Diseases [ICD-10] [79], with the underlying cause codes X64 to X87.0. All suicides to persons age 18 and above (cases) were coded 1. Persons dying of natural causes (after eliminating homicides and accidents) were coded 0 and used as controls. Like the suicides, analysis was limited to individuals dying in their current state of residence. Due to serious technical difficulties encountered (computer memory problems, convergence problems, etc.) in analyzing all deaths from natural causes (nearly 10 million) a $20 \%$ simple random sample was selected for each year studied. The deaths for all 5 years were then pooled into one concatenated file. The resulting deaths from natural causes per year (after sampling) were as follows: 369,023 (in 2000), 370,628 (in 2001), 429,099 (in 2002), 377,029 (in 2003), and 368,504 (in 2004). In all, there were 131,636 suicides, and $1,914,283$ sampled deaths from natural sources. Thus, the effective sample size at the individual level comprised $2,045,919$ cases. 
Individual level variables

Day of the week was treated as a series of dummy variables with one each for Monday, Tuesday, Wednesday, Thursday, Friday, and Saturday. Sunday was treated as the reference category for comparison. To measure season, we collapsed the 12 months in the calendar year into autumn (September, October, and November), spring (March, April, and May), and summer (comprising the months June, July, and August). The reference group was winter (December, January, and February). Owing to the fact that the data were pooled from deaths occurring in five different years, period effects might be present. It is conceivable that any single year is atypical and that the number of suicides may be affected by extraneous national and even international events. To control for period effects as well as possible trends in the data, analysis employed year of death as an independent variable. The variable was measured as a series of dummy variables. There was one each for 2001 , 2002, 2003, and 2004. The year 2000 was the reference category for comparison purposes.

Studies in the United States consistently show that there are substantial disparities in rates and risks of suicide by race/ethnicity $[11,30,38,40]$. Racial differences in suicide have also been reported in South Africa, with whites experiencing much higher rates than Blacks, Coloureds or Asians in major South African cities [9]. It has also been suggested that seasonality might affect non-whites and whites differently $[7,54,74]$. The present report, therefore, controlled for race/ethnicity. The variable comprised nonHispanic African Americans, non-Hispanic native Americans, non-Hispanic Asians, and Hispanics. Each of these groups was coded 1, and non-Hispanic Whites were used as the reference category. Marital status has figured prominently in many studies as a significant predictor of suicide and parasuicide $[13,15,25,29]$. The covariate was measured by a set of dummy variables, with one each for single, widowed, separated, or divorced. Those married at the time of death constituted the reference category. Persons with missing marital status information were deleted from the analysis. Age at death was captured by leaving it in its interval form. For sex, females were the omitted group. Both age and sex were included as demographic control variables. The MCDF lacks many socioeconomic variables. Education, the only one collected in all states was used as a control variable. The covariate was left in its format as highest grade completed. The data contained a large number of missing cases, so the mean value (high school education) was substituted for persons with missing information. City size of residence was left in its ordinal format. Inclusion of city size is important for reassessing findings in some recent studies that rural areas have significantly higher suicide rates than urban areas [32, 63].
State level variables

The main level 2 variable was the state suicide rate. Its inclusion was based on the reasoning that high suicides in a state increase not only awareness of suicide, but attitudes favorable to suicidal behavior. As Stack and Kposowa [75, p. 41] explain, "In a community with a high suicide rate, there are proportionately more persons committing suicide and, hence, more cases that offer excuses for suicide." The variable was measured as the number of suicides per 100,000 resident population in 1999. The second level 2 variable was physician supply, measured as the number of physicians per 100,000 population in 2000 . Utilization of the variable in this research was informed by past ecological studies that have shown a relationship between availability of primary care physicians and both morbidity and mortality $[6,70]$. The unemployment rate was measured as the percent of the civilian labor force that was unemployed in 2000. Unemployment has been used extensively in suicide research with mixed results [27]. The present study offers an opportunity to ascertain its association with suicide in a multi-level framework. Divorce was measured as divorces per 1,000 resident population in 2000. The variable has been generally used as an indicator of social integration or social fragmentation $[8,12,20,25$, $36,38]$. Both percent college educated, 2000 and the Gini Index of income inequality, 2000 were used as socioeconomic controls. Higher values on Gini (which ranges from 0 to 1 ) indicate higher income inequality and thus higher relative deprivation. With regard to region, we divided the US into West and non-Western States, with non-West used as reference. The rationale for this classification was based on research in sociological science that finds Western states consistently having the highest suicide rates than the rest of the country [8, 36, 38]. Western states were limited to California, Oregon, Nevada, and Washington.

\section{Results}

\section{Descriptive findings}

Figure 1 presents descriptive results on pooled suicides by day of the week covering the period 2000-2004 inclusive. The highest percentage of suicides occurred on Wednesday (24.6\%). The percentages dropped suddenly on Thursday $(11.1 \%)$, Friday $(11.2 \%)$, and Sunday (11.8\%). Suicides then rose to $12.7 \%$ on Tuesday, $14.3 \%$ on Monday, and $14.4 \%$ on Saturday. On the whole, descriptive statistics showed a single suicide peak on Wednesday and the lowest point on Thursday (11.1\%). Thursday and Friday were the days with the fewest suicides in the 5 years of data combined. 
Fig. 1 Daily distribution of suicides, United States 2000 2004

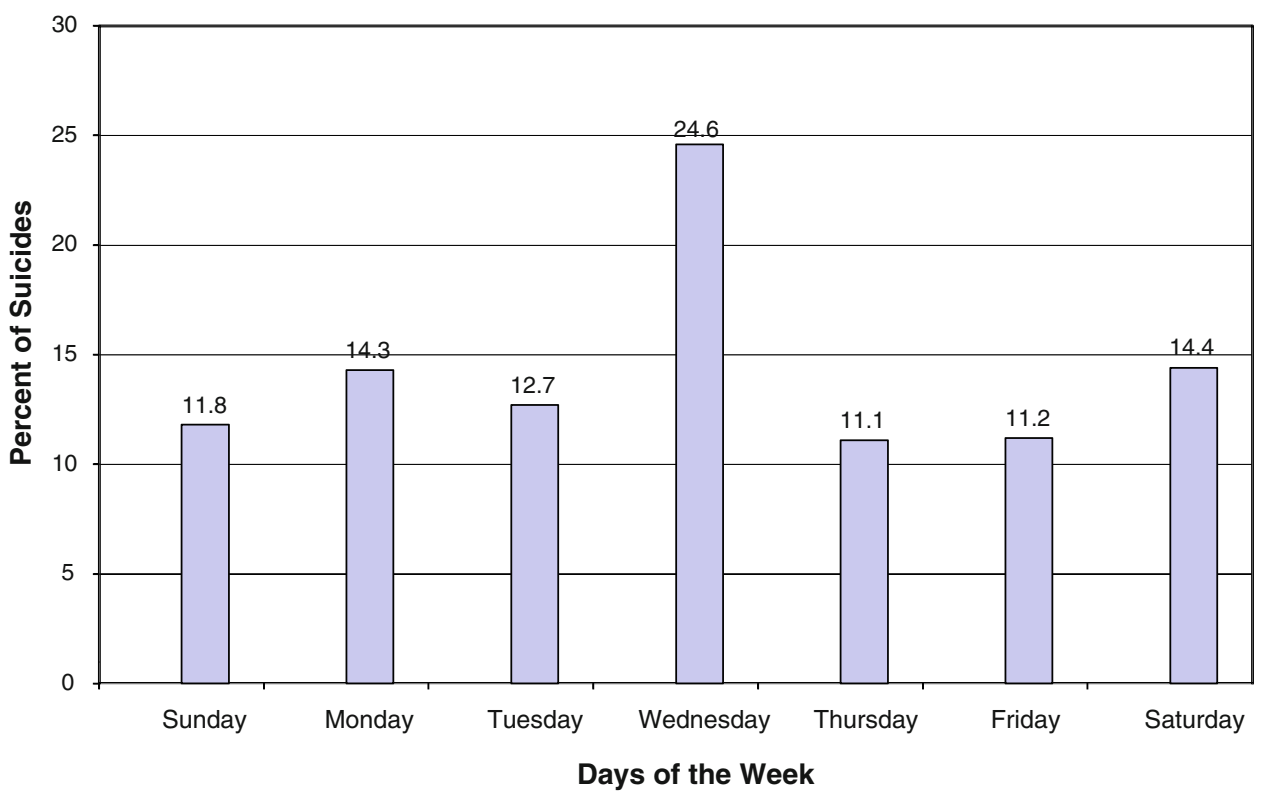

Figure 2 shows graphic results with regard to seasons and suicide. As may be seen, $26 \%$ of all suicides took place in summer, and $25.8 \%$ occurred in spring. Autumn months posted $24.4 \%$ and the lowest incidence was in the winter $(23.8 \%)$. On the whole, the descriptive results seem to suggest that suicides are highest in the summer months, followed closely by months in winter.

\section{Multivariate findings}

The remainder of the analysis focuses on examining the association between days and seasons and the odds of suicide, taking into account the association of other variables. Table 1 presents hierarchical logistic regression results showing the effects of days and season on suicide in 2000 through 2004. As may be seen, the estimated effects are generally in agreement with the descriptive findings shown earlier in Figs. 1 and 2. With regard to days of the week, the Wednesday effect on suicide was much stronger than that observed for any other day. Individuals were a little over $99 \%([\mathrm{OR}-1] \times 100)$ more likely to kill themselves on Wednesday than on Sunday. They were over $55 \%$ as likely to kill themselves on Monday as on Sunday (OR 1.556, CI 1.519, 1.598), and suicides were 62\% more likely to take place on Tuesday than on Sunday (OR 1.623, CI $1.581,1.667)$. Individuals were also nearly 1.5 times as likely to have died of suicide on Thursday as on Sunday, and the odds of suicide were $26 \%$ more elevated on Friday
Fig. 2 Seasonal distribution of suicides, United States 20002004

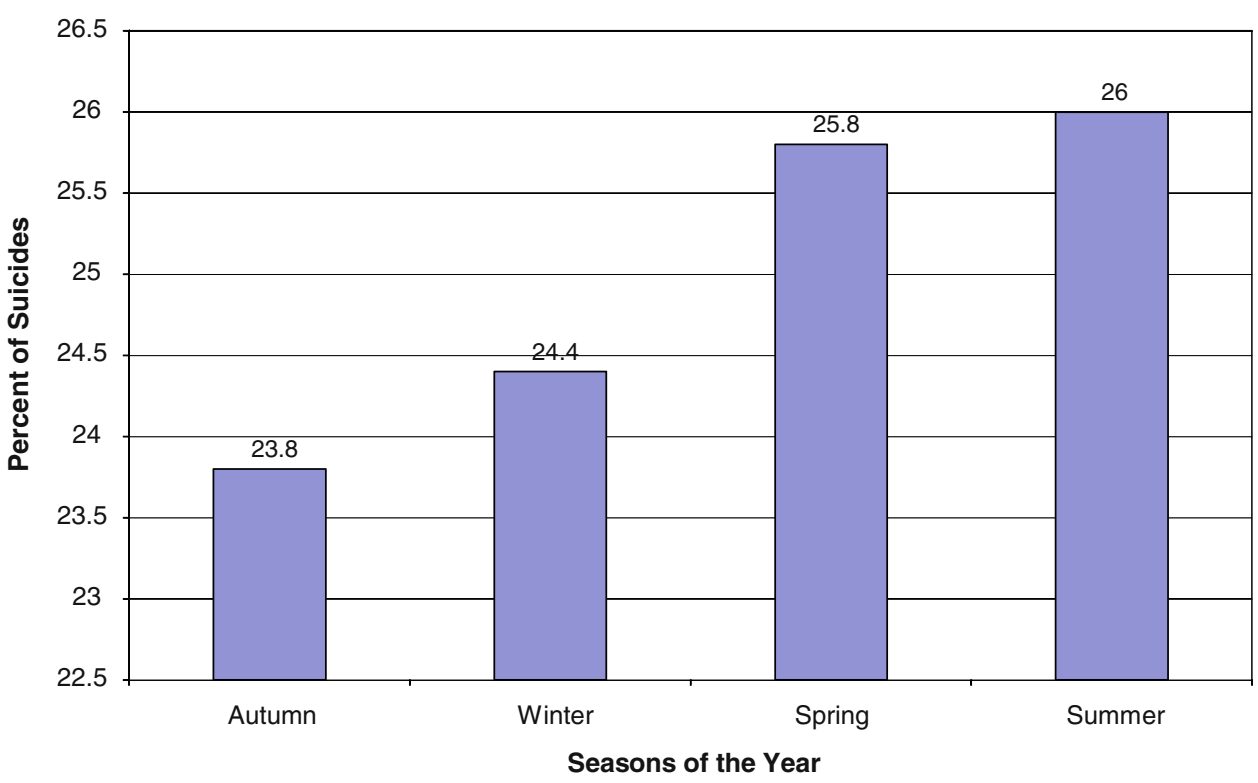


Table 1 Hierarchical logistic regression results of the association of temporal factors and suicide mortality, entire sample, United States, 2000$2004(N=2,045,919)$

\begin{tabular}{|c|c|c|c|c|c|}
\hline Variables & $\beta$ & $t$ value & Prob. & OR & $95 \% \mathrm{CI}$ \\
\hline \multicolumn{6}{|l|}{ Individual level (1) } \\
\hline Intercept & 0.5995 & 3.76 & 0.0005 & 1.821 & $1.321,2.510$ \\
\hline \multicolumn{6}{|l|}{ Day of the Week } \\
\hline Sunday & Reference & & & 1.000 & Reference \\
\hline Monday & 0.4422 & 34.18 & 0.0001 & 1.556 & $1.519,1.598$ \\
\hline Tuesday & 0.4847 & 35.86 & 0.0001 & 1.623 & $1.581,1.667$ \\
\hline Wednesday & 0.6901 & 58.94 & 0.0001 & 1.994 & $1.949,2.040$ \\
\hline Thursday & 0.3819 & 27.40 & 0.0001 & 1.465 & $1.426,1.506$ \\
\hline Friday & 0.2358 & 17.34 & 0.0001 & 1.263 & $1.232,1.300$ \\
\hline Saturday & 0.4597 & 35.20 & 0.0001 & 1.583 & $1.543,1.625$ \\
\hline \multicolumn{6}{|l|}{ Season of the year } \\
\hline Winter & Reference & & & 1.000 & Reference \\
\hline Autumn & 0.1009 & 10.50 & 0.0001 & 1.106 & $1.086,1.127$ \\
\hline Spring & 0.1422 & 14.99 & 0.0001 & 1.153 & $1.132,1.174$ \\
\hline Summer & 0.1766 & 18.60 & 0.0001 & 1.193 & $1.171,1.216$ \\
\hline \multicolumn{6}{|l|}{ Year of death } \\
\hline 2000 & Reference & & & 1.000 & Reference \\
\hline 2001 & 0.0274 & 2.51 & 0.0121 & 1.028 & $1.006,1.050$ \\
\hline 2002 & -0.0580 & -5.50 & 0.0001 & 0.944 & $0.924,0.967$ \\
\hline 2003 & -0.0035 & -0.30 & 0.7612 & 0.996 & $0.974,1.019$ \\
\hline 2004 & 0.0923 & 8.58 & 0.0001 & 1.097 & $1.074,1.120$ \\
\hline \multicolumn{6}{|l|}{ Sex } \\
\hline Female & Reference & & & 1.000 & Reference \\
\hline Male & 1.0735 & 134.14 & 0.0001 & 2.926 & $2.880,2.972$ \\
\hline \multicolumn{6}{|l|}{ Race/ethnicity } \\
\hline White & Reference & & & 1.000 & Reference \\
\hline African American/Black & -1.3542 & -98.41 & 0.0001 & 0.258 & $0.251,0.265$ \\
\hline Native American & -0.4619 & -12.03 & 0.0001 & 0.630 & $0.584,0.679$ \\
\hline Asian & -0.0752 & -3.05 & 0.0023 & 0.928 & $0.884,0.973$ \\
\hline Hispanic & -0.5129 & -34.36 & 0.0001 & 0.599 & $0.581,0.617$ \\
\hline \multicolumn{6}{|l|}{ Marital status } \\
\hline Married & Reference & & & 1.000 & Reference \\
\hline Divorced & 0.3222 & 36.69 & 0.0001 & 1.380 & $1.357,1.404$ \\
\hline Single & -0.1556 & -15.77 & 0.0001 & 0.856 & $0.839,0.872$ \\
\hline Widowed & 0.3469 & 28.28 & 0.0001 & 1.415 & $1.381,1.491$ \\
\hline Education & 0.0741 & 53.82 & 0.0001 & 1.077 & $1.073,1.080$ \\
\hline \multicolumn{6}{|l|}{ Place of residence } \\
\hline Non-metropolitan & Reference & & & 1.000 & Reference \\
\hline Metropolitan & -0.1253 & -14.31 & 0.0001 & 0.882 & $0.867,0.897$ \\
\hline City size of residence & -0.0359 & -10.96 & 0.0001 & 0.965 & $0.958,0.971$ \\
\hline Age & -0.0902 & -369.48 & 0.0001 & 0.914 & $0.913,0.914$ \\
\hline \multicolumn{6}{|l|}{ State level (2) } \\
\hline Suicide rate (1999) & 0.0408 & 15.11 & 0.0001 & 1.042 & $1.036,1.047$ \\
\hline Physician supply (2000) & -0.0018 & -12.39 & 0.0001 & 0.998 & $0.997,0.998$ \\
\hline \% Unemployed (2000) & 0.0129 & 1.94 & 0.0583 & 1.013 & $0.999,1.026$ \\
\hline \% Divorced (2000) & 0.0173 & 2.05 & 0.0467 & 1.017 & $1.000,1.035$ \\
\hline$\%$ College educated (2000) & 0.0226 & 12.29 & 0.0001 & 1.023 & $1.019,1.027$ \\
\hline
\end{tabular}


Table 1 continued

\begin{tabular}{|c|c|c|c|c|c|}
\hline Variables & $\beta$ & $t$ value & Prob. & OR & $95 \% \mathrm{CI}$ \\
\hline Gini index (2000) & -0.6773 & -2.04 & 0.0473 & 0.508 & $0.260,0.992$ \\
\hline Region (West = 1) (2000) & -0.0159 & -0.80 & 0.4301 & 0.984 & $0.945,1.025$ \\
\hline Covariance parameter & 0.0006 & 8.68 & & & \\
\hline-2 Res log pseudo-likelihood & $1,408,210$ & & & & \\
\hline Generalized Chi-square & $1,887,002$ & & & & \\
\hline Generalized Chi-square/df & 0.92 & & & & \\
\hline Suicides & 131,636 & & & & \\
\hline Natural deaths & $1,914,283$ & & & & \\
\hline Total observations (level 1) & $2,045,919$ & & & & \\
\hline Total observations (level 2) & 51 & & & & \\
\hline Max obs. per state & 214,080 & & & & \\
\hline
\end{tabular}

$\beta$ unstandardized logistic coefficient, $O R$ odds ratio, $C I$ confidence interval

than on Sunday. Persons were 58\% more likely to suicide on Saturday than on Sunday (OR 1.583, CI 1.543, 1.625).

As for seasons of the year, results show that suicides were a little over $19 \%$ as likely to occur in summer as in winter (OR 1.193, CI 1.171-1.216). They were 15\% more likely to take place in spring (OR 1.153, CI 1.132-1.174) than in winter, and they were nearly $11 \%$ as likely to occur in summer as in winter (OR 1.106, CI 1.086-1.127). When year of death was considered, findings revealed no consistent trends in death. The year 2001 was barely significant, although the regression coefficient was in the positive direction (OR 1.028, CI 1.006-1.050). Suicides were 5.6\% less likely to take place in 2002 than in 2000 . There was no significant difference in risk between 2003 and 2000, but in 2004 the risk of suicide mortality was nearly $10 \%$ more elevated than in 2000 (OR 1.097, CI 1.074-1.120).

Consistent with prior research, males were over 2.9 times more likely to commit suicide than their female counterparts (OR 2.926, CI 2.880-2.972). When race/ethnicity was considered, African Americans, American Indians, Asians, and Hispanics all had much lower risks of suicide than whites, with African Americans showing especially lower risk (OR 0.258, CI 0.251-0.265). Divorced persons were $38 \%$ more likely to commit suicide than the married. Single/never married persons exhibited lower suicide risk than the married, but widowed persons experienced a suicide risk that was over 1.4 times that of married persons. Education elevated suicide risk (OR 1.077, CI 1.0731.080). Findings further show that individuals living in metropolitan areas were less likely to kill themselves than their counterparts living outside metro areas (OR 0.965, CI 0.958-0.971). In a similar manner, the greater the size of the city of residence, the lower the suicide risk.

We turn next to level 2 results, which are also shown in Table 1. As may be observed in the table, the state suicide rate elevated individual risk of dying from suicide (OR
1.042, CI 1.036-1.047). Greater supply of physician resources in a state significantly reduced individual suicide risk (OR 0.998, CI 0.997-0.998). The state unemployment rate was not significantly associated with suicide, but the divorce rate elevated individual suicide risk, although by a very small margin. The higher the percentage of college educated persons in a state, the higher the individual suicide risk (OR 1.023, CI 1.019-1.027). The state Gini Coefficient had a marginal effect on individual suicide risk, but in the negative direction. There was no significant difference between Western and non-Western states in individual suicide risk. Finally, the variance of the random state intercepts on the logit scale $\left(\sigma_{\mathrm{s}}^{2}=0.0006\right)$ was statistically significant, suggesting the existence of state differentials in individual odds of suicide.

One of the research questions posed in the introduction was to address whether there are racial/ethnic differences regarding the impact of seasonality on suicide. Due to the reduced number of suicides, the various non-White groups were combined for comparison with non-Hispanic whites. Relevant results are presented in Table 2. The first three columns show results for Whites and the last three columns have findings for non-Whites.

As may be seen in the table, the daily effects were relatively similar in both groups. Among Whites, the peak in suicides was on Wednesday when the odds ratio was 1.98 (CI 1.94-2.03). Among non-Whites, Wednesday was also the peak in suicides, but with a slightly stronger odds ratio (2.06, CI 1.96-2.20). In the non-White group, individuals were $93 \%$ more likely to die from suicide on Saturday than on Sunday (OR 1.93, CI 1.81-2.05). In the White group, however, the second weekly peak was not Saturday, but Tuesday, when the suicide risk was $61 \%$ more elevated than on Sunday.

When seasons were considered, spring was a clear suicide peak for Whites (OR 1.43, CI 1.12-1.17), but for 
Table 2 Hierarchical logistic regression results of the association of temporal factors and suicide mortality, White and Non-White Samples, United States, 2000-2004

\begin{tabular}{|c|c|c|c|c|c|c|}
\hline \multirow[t]{2}{*}{ Variables } & \multicolumn{3}{|l|}{ Whites } & \multicolumn{3}{|l|}{ Non-Whites } \\
\hline & $\beta$ & OR & $95 \% \mathrm{CI}$ & $\beta$ & OR & $95 \% \mathrm{CI}$ \\
\hline \multicolumn{7}{|l|}{ Individual level (1) } \\
\hline Intercept & $0.4053 *$ & 1.50 & $1.05,2.14$ & $2.4441 * *$ & 11.52 & $4.36,30.43$ \\
\hline \multicolumn{7}{|l|}{ Day of the week } \\
\hline Sunday & & 1.00 & Reference & & 1.00 & Reference \\
\hline Monday & $0.4338 * *$ & 1.54 & $1.50,1.59$ & $0.4676^{* *}$ & 1.60 & $1.50,1.70$ \\
\hline Tuesday & $0.4771 * *$ & 1.61 & $1.56,1.66$ & $0.5058 * *$ & 1.66 & $1.55,1.77$ \\
\hline Wednesday & $0.6815 * *$ & 1.98 & $1.93,2.03$ & $0.7303 * *$ & 2.06 & $1.96,2.20$ \\
\hline Thursday & $0.3645 * *$ & 1.44 & $1.40,1.48$ & $0.4559 * *$ & 1.58 & $1.47,1.69$ \\
\hline Friday & $0.2044 * *$ & 1.23 & $1.19,1.26$ & $0.3915^{* *}$ & 1.48 & $1.38,1.58$ \\
\hline Saturday & $0.4161 * *$ & 1.52 & $1.47,1.56$ & $0.6564 * *$ & 1.93 & $1.81,2.05$ \\
\hline \multicolumn{7}{|l|}{ Season of the year } \\
\hline Winter & & 1.00 & Reference & & 1.00 & Reference \\
\hline Autumn & $0.0957 * *$ & 1.10 & $1.08,1.12$ & $0.1279 * *$ & 1.14 & $1.08,1.19$ \\
\hline Spring & $0.1356^{* *}$ & 1.43 & $1.12,1.17$ & $0.1749 * *$ & 1.19 & $1.14,1.25$ \\
\hline Summer & $0.1765 * *$ & 1.19 & $1.17,1.22$ & $0.1777 * *$ & 1.19 & $1.14,1.25$ \\
\hline \multicolumn{7}{|l|}{ Year of death } \\
\hline 2000 & & 1.00 & Reference & & 1.00 & Reference \\
\hline 2001 & $0.0346^{* *}$ & 1.04 & $1.01,1.06$ & -0.0025 & 0.99 & $0.95,1.05$ \\
\hline 2002 & $-0.0568 * *$ & 0.94 & $0.92,0.97$ & $-0.0597 *$ & 0.94 & $0.89,0.99$ \\
\hline 2003 & -0.0147 & 0.98 & $0.96,1.01$ & $0.0719 * *$ & 1.07 & $1.02,1.14$ \\
\hline 2004 & $0.0961 * *$ & 1.10 & $1.07,1.12$ & $0.1026^{* *}$ & 1.11 & $1.05,1.17$ \\
\hline \multicolumn{7}{|l|}{ Sex } \\
\hline Female & & 1.00 & Reference & & 1.00 & Reference \\
\hline Male & $1.0595 * *$ & 2.88 & $2.84,2.93$ & $1.1652 * *$ & 3.21 & $3.08,3.34$ \\
\hline \multicolumn{7}{|l|}{ Marital status } \\
\hline Married & & 1.00 & Reference & & 1.00 & Reference \\
\hline Divorced & $0.3537 * *$ & 1.42 & $1.40,1.45$ & 0.0051 & 1.01 & $0.96,1.06$ \\
\hline Single & $-0.1322 * *$ & 0.88 & $0.86,0.89$ & $-0.4157 * *$ & 0.60 & $0.63,0.69$ \\
\hline Widowed & $0.3382 * *$ & 1.40 & $1.37,1.44$ & $0.2901 * *$ & 1.34 & $1.24,1.44$ \\
\hline Education & $0.0748 * *$ & 1.08 & $1.07,1.08$ & $0.0641 * *$ & 1.07 & $1.07,1.07$ \\
\hline \multicolumn{7}{|l|}{ Place of residence } \\
\hline Non-metropolitan & & 1.00 & Reference & & 1.00 & Reference \\
\hline Metropolitan & $-0.1318^{* *}$ & 0.88 & $0.86,0.89$ & $-0.1127 * *$ & 0.89 & $0.84,0.94$ \\
\hline City size of residence & $-0.0352 * *$ & 0.97 & $0.96,0.97$ & $-0.0801 * *$ & 0.92 & $0.91,0.93$ \\
\hline Age & $-0.0892 * *$ & 0.91 & $0.91,0.91$ & $-0.0966^{* *}$ & 0.91 & $0.91,0.91$ \\
\hline \multicolumn{7}{|l|}{ State level (2) } \\
\hline Suicide Rate (1999) & $0.0384 * *$ & 1.04 & $1.03,1.06$ & $0.0863 * *$ & 1.09 & $1.07,1.11$ \\
\hline Physician supply, (2000) & $-0.0021 * *$ & 0.99 & $0.99,0.99$ & $-0.0013^{* *}$ & 0.99 & $0.99,0.99$ \\
\hline \% Unemployed (2000) & 0.0109 & 1.01 & $0.99,1.03$ & $0.0527 * *$ & 1.05 & $1.05,1.09$ \\
\hline \% Divorced (2000) & $0.0201 *$ & 1.02 & $1.00,1.04$ & $-0.1370^{* *}$ & 0.87 & $0.82,0.92$ \\
\hline$\%$ College educ. (2000) & $0.0231 * *$ & 1.03 & $1.02,1.03$ & $0.0411 * *$ & 1.02 & $1.03,1.05$ \\
\hline Gini index (2000) & -0.1806 & 0.83 & $0.39,1.75$ & $-7.0358^{* *}$ & 0.01 & $0.01,0.01$ \\
\hline Region (West = 1) & 0.0028 & 1.00 & $0.96,1.05$ & $0.1923 * *$ & 1.21 & $1.07,1.37$ \\
\hline Covariance parameter & $0.0007 * *$ & & & $0.0059 * *$ & & \\
\hline-2 Res log pseudo-L & $11,298,510$ & & & $2,813,609$ & & \\
\hline Generalized Chi-square & $1,486,057$ & & & 466,997 & & \\
\hline
\end{tabular}


Table 2 continued

\begin{tabular}{|c|c|c|c|c|c|c|}
\hline \multirow[t]{2}{*}{ Variables } & \multicolumn{3}{|l|}{ Whites } & \multicolumn{3}{|c|}{ Non-Whites } \\
\hline & $\beta$ & OR & $95 \% \mathrm{CI}$ & $\beta$ & OR & $95 \% \mathrm{CI}$ \\
\hline Gener. Chi-Square/df & 0.89 & & & 1.26 & & \\
\hline Suicides & 111,385 & & & 20,251 & & \\
\hline Natural deaths & $1,565,251$ & & & 349,032 & & \\
\hline$N$ (level 1) & $1,676,636$ & & & 369,283 & & \\
\hline$N$ (level 2) & 51 & & & 51 & & \\
\hline Max obs. per state & 155,830 & & & 58,250 & & \\
\hline
\end{tabular}

$\beta$ unstandardized logistic coefficient, $O R$ odds ratio, $C I$ confidence interval

* Significant at $P<0.05$, ** significant at $P<0.01$

non-Whites, suicides tended to peak in summer followed closely by spring. Indeed, the seasonal distribution appears more evenly distributed among non-Whites than Whites. Year of death exhibited slightly divergent patterns in the two groups. For instance, year 2001 elevated suicide risk in whites, but not in non-whites. Similarly, year 2003 increased suicide risk in non-whites, but the covariate did not reach statistical significance among whites; indeed, it was in the negative direction. The only consistent yearly effect in Whites and non-Whites was 2004 when both groups experienced much higher suicide odds than in 2000.

White males were nearly 2.8 times more likely to die of suicide than white females, and non-White males were 3.2 times as likely to die of suicide as their non-White female counterparts. While divorce increased the risk of suicide in Whites (OR 1.42, CI 1.40-1.45), it had no significant effect in the non-White group.

When level 2 variables were examined, findings showed that the state suicide rate increased suicide risk in Whites and non-Whites alike. Physician supply reduced the risk of suicide in both groups. While the state unemployment rate had no significant association with suicide among Whites, in non-Whites the association was statistically significant (OR 1.05, CI 1.05-1.09). The state divorce rate was barely significant, but positive in the White sample, it was negatively associated with suicide in the non-White sample (OR 0.87, CI 0.82-0.92). Likewise, while the Gini Index of income inequality did not reach statistical significance in Whites, it was very strongly related to suicide in the non-White group (OR 0.01, CI 0.01-0.01). Western states did not significantly predict suicide for Whites, but they elevated suicide odds among non-Whites (OR 1.21, CI 1.07-1.37).

\section{Discussion}

Several research questions were posed at the beginning of this paper. The first two have been unequivocally answered by the data analysis. Results have shown both significant daily and significant seasonal variations in suicide. Suicides are more likely to occur in summer and spring and significantly less likely in fall and winter. This is consistent with numerous recent studies that have reported a suicide peak in spring or summer [31, 44, 60, 62]. Results from the data analysis challenge some previous studies [68] that reported an inverse relationship between temperature and suicide, because such a relationship implies that higher suicide deaths occur in winter and autumn and lower deaths take place in spring and summer. Results also challenge findings of a recent study [27] that emphatically stated that suicides peak in winter. In the present study, the highest peak was observed in summer.

As far as daily distributions are concerned, findings in this study reveal that suicides are concentrated on Wednesday. This may well be the first US study to demonstrate a Wednesday suicide peak. Past work has found Monday as the peak day. Given that Wednesday, not Monday was observed as the day with the highest suicide occurrence, results are at odds with Durkheim's [18] observation that suicides are higher at the beginning of new periods. Results reported here disconfirm research in the United States by Maldonado and Kraus [49] and in Australia by Hassan [24] that found most suicides occurring on Monday. Findings are also at odds with those noted by Page et al. [59] for the United Kingdom that suicides took place most often in winter, notably in January. Indeed, Page et al. [59, p. 109] expressly stated that their study did not support prior findings of a spring or summer peak in suicide. While Maldonado and Kraus [49] reported mixed results regarding months of the year (seasons), in the present study, a clear pattern emerged, with suicides peaking in summer.

While the effects of days and seasons on suicide should not be interpreted as climatic or environmental determinism, they do highlight periods when people are significantly more likely to be victimized. Thus, at the clinical level, the present research is important in the behavioral sciences (e.g., psychology, psychiatry, social work, counseling, and applied sociology). Knowledge of day or season when 
suicides are more likely to happen can possibly help clinicians and therapists in advising patients and potential victims when they present themselves with depressive and associated symptoms. A clinician could become more proactive, whether through medication or advice, thereby intervening to prevent death.

In view of the finding that most suicides tend to occur on Wednesday compared to other days of the week, and that the likelihood of death is also highest in summer, compared to winter, the question may be asked as to whether psychosocial problems are especially more pernicious on Wednesday, compared to say, Weekends, or in summer, compared to Winter. If psychological and certain social problems are significantly more likely to be experienced on Wednesday, then future research could try to disentangle what these problems are, with the view to partialling out their link to Wednesday.

It is plausible that the finding with regard to season is due to co-morbidity. Some past studies [47], and to some extent popular folklore in many cultures allude to winter months as likely to have higher levels of suicide. Reasons for this are generally given in terms of winter months having less sunshine on average, and thus raising the stakes for conditions such as depression, anxiety, affective disorders, greater suicide ideation, and thus suicidal behavior [78]. Another tack in this regard is that two major 'family' holidays (Christmas and the New Year) take place in the winter (at least in the western hemisphere). Winter holidays are viewed as being especially stressful for persons who lack social support due to absence of significant others (family, friends, spouses, and other loved ones). According to comorbidity arguments [14], the incidence of depression, anxiety, seasonal affective disorder, and other psychiatric conditions may be especially high during winter and therefore, suicide risks and rates would be high. Research has shown, however, that a condition such as seasonal affective disorder occurs during autumn and winter [14]. The finding here and in other studies that suicides peak in summer and spring challenges any view of seasonal affective disorder having an effect on the seasonality of suicides.

The argument about the concentration of many psychiatric and psychological disorders in winter having been discarded in the present study, could it be, for example, that social integration, as proposed by Durkheim is actually much higher in winter than in summer? After all, despite the less sunny weather in winter, people may spend more time at home, with family and friends. With increasing technology, perhaps, they also spend more time on the telephone, computers, and other entertainment gadgets when the weather gets bad. In an information age (cell phones, emails, and other instant means of communication), physical separation need not necessarily imply complete lack of social support or networking. Thus, the mere fact of cold weather (in the winter) should not be assumed as bringing a reduction in social ties, or as promoting depression and higher suicidal behavior. Disentangling the various ideas raised here presents a clear research challenge in the quest to increase more fully our knowledge of the link between temporal factors and suicide.

For suicide research on seasonality to advance and become more consistent, investigators may need to make greater use of multi-level designs. Events which are frequently viewed as individual behavior may also be influenced by contextual factors. In the present study, state suicide rates significantly affected individual's suicide behavior. How to explain this finding?

Consistent with social learning and differential association theories of deviant behavior [1-3, 76], persons living in states or localities with high suicide rates may have higher exposure to definitions favorable to suicide acceptance, and this in turn may increase their odds of committing suicide. Prevailing social, economic, and even political conditions in a state may further affect individual's suicidal behavior by maintaining an environment in which people's aspirations are thwarted and dreams of a better tomorrow are deferred.

With regard to racial/ethnic differences, Stack [74, p. 321] reported that white suicides peak on Monday, adding that there were 8.25 additional suicides on Mondays, compared to Sundays, and that Saturday was the trough in white suicides. Likewise, McIntosh and Lester [54] found that white and black suicides peaked on Mondays, although the peak was less pronounced for Blacks. Data analysis for this study failed to find support for Stack's [74] contention of white suicides peaking on Monday, or McIntosh and Lester's [54] suggestion of both white and black suicides also peaking on Monday. Analysis has clearly shown that for white suicides, Wednesday is the peak. Although Blacks were not specifically studied, and they were lumped with other minority groups, findings here have shown that non-White suicides also peaked on Wednesday, followed not by Monday, but by Saturday. In contrary to Stack's [74] report, the trough in white suicides in the present study was not Saturday, but Friday. The trough in non-White suicides was also on Friday.

A consistent and notable finding is that divorce places a person at an especially high risk of becoming a suicide victim. How to interpret the divorce findings? Sociologist Durkheim [18] informed us a century ago that a breakdown in social integration through divorce is a crisis and a profoundly stressful life event. This is now a well-documented observation in mental health, health psychology, psychosomatic medicine, and family therapy [25, 48, 65]. Separated and divorced individuals have been found to be over-represented in the psychiatric patient population, for instance. Separated people are more likely to be involved 
in automobile accidents than non-separated people [39]. Marital separation, as opposed to non-separation, is associated with higher rates of illness and disability as well as high death rates due to suicide, homicide, and other causes of mortality [37, 67]. Findings from this study confirm once again that divorce is a non-trivial risk factor for suicide at both the individual and contextual levels.

Findings confirm that there are still significant ruralurban differences in suicide risk in that metropolitan areas experienced lower risks than non-metropolitan areas. Results are consistent with those reported in recent research [32, 38, 63].

Commenting on the on rural-urban differentials in suicide risk, Kposowa [38] argued that completed suicides may be influenced by emergency response services and the existence of nearby trauma centers. Simply put, in localities with rapid emergency response, timely arrival at the scene of a suicide event could make the difference between life and death. In general, emergency response services as well as trauma centers are more likely to be concentrated in large urban centers than in smaller cities or rural areas. Implicit in this argument is that at some point in American history, urban areas might have experienced much higher suicide rates than rural areas, but with advances in technology, especially communication and transportation centered in metropolitan areas, there has been a gradual shift in suicide occurrence that disadvantages rural communities $[17,28]$.

In general, results showed that climatic factors should not be discounted in efforts to explain suicide. In this regard, results support Morselli's [55] admonition that the regularity observed between season and suicide may be too great for it to be attributed to chance of the human will.

Open Access This article is distributed under the terms of the Creative Commons Attribution Noncommercial License which permits any noncommercial use, distribution, and reproduction in any medium, provided the original author(s) and source are credited.

\section{References}

1. Akers R (1998) Social learning and social structure: a general theory of crime and deviance. Northeaster University Press, Boston

2. Akers R (2004) Criminological theories: introduction, evaluation, and application. Roxbury Publishing Company, Los Angeles

3. Baller RD, Shin DJ, Richardson K (2005) An extension and test of Sutherland's concept of differential social organization: the geographic clustering of Japanese suicide and homicide rates. Suicide Life Threat Behav 35:343-355

4. Barraclough BM (1976) Time of day chosen for suicide. Psychol Med 6:303-305

5. Benedito-Silva AA, Pires ML, Calil HM (2007) Seasonal variation of suicide in Brazil. Chronobiol Int 24(4):727-737

6. Blakely T, Lochner K, Kawachi I (2002) Metropolitan area income inequality and self-rated health-a multi-level study. Soc Sci Med 54:65-77
7. Bollen KA (1983) Temporal variations in mortality: a comparison of U.S. suicides and motor vehicle fatalities, 1972-1976. Demography 20:45-59

8. Breault KD (1986) Suicide in America: a test of Durkheim's theory of religious and family integration, 1933-1980. Am J Sociol 92:628-656

9. Burrows S, Laflamme L (2006) Suicide mortality in South Africa: a city-level comparison across socio-demographic groups. Soc Psychiatry Psychiatr Epidemiol 41(2):108-114

10. Cohn EG (1990) Weather and crime. Br J Criminol 30:51-64

11. Compton MT, Thompson NJ, Kaslow NJ (2005) Social environment factors associated with suicide attempt among lowincome African Americans: the protective role of family relationships and social support. Soc Psychiatry Psychiatr Epidemiol 40:175-185

12. Congdon P (1996) Suicide and parasuicide in London: a small area study. Urban Stud 33:137-158

13. Cooper J, Husain N, Webb R, Waheed W, Kapur N, Guthrie E, Appleby L (2006) Self-harm in the UK: differences between South Asians and Whites in rates, characteristics, provision of service and repetition. Soc Psychiatry Psychiatr Epidemiol 41:782-788

14. Deisenhammer EA (2003) Weather and suicide: the present state of knowledge on the association of meteorological factors with suicidal behavior. Acta Psychiatr Scand 108:402-409

15. Desaulniers J, Daigle MS (2008) Inter-regional variations in men's attitudes, suicide rates and sociodemographics in Quebec (Canada). Soc Psychiatry Psychiatr Epidemiol 43:445-453

16. Dublin IL (1963) Suicide: a sociological and statistical study. Ronald Press, New York

17. Dudley M, Kelk N, Florio T, Howard J, Waters B, Haski C, Alcock M (1997) Suicide among young rural Australians 19641993: a comparison with metropolitan trends. Soc Psychiatry Psychiatr Epidemiol 32:251-260

18. Durkheim E (1897/1966) Suicide: a study in sociology. Translated by Spaudlin JA and Simpson G. The Free Press, New York

19. Eastman CI (1990) Natural summer and winter sunlight exposure patterns in seasonal affective disorder. Physiol Behav 48:611-616

20. Evans J, Middleton N, Gunnell D (2004) Social fragmentation, severe mental illness and suicide. Soc Psychiatry Psychiatr Epidemiol 39:165-170

21. Edwards JE, Whitlock FE (1968) Suicide and attempted suicide in Brisbane. Med J Psychiatry 1:932-938

22. Gabennesch H (1988) When promises fail. Soc Forces 67:129_ 145

23. Hakko H, Räsänen $P$, Tiihonen J (1998) Seasonal variation in suicide occurrence in Finland. Acta Psychiatr Scand 8(2):92-97

24. Hassan R (1995) Suicide Explained. Melbourne University Press, Australia

25. Hawthorne G (2008) Perceived social isolation in a community sample: its prevalence and correlates with aspects of people's lives. Soc Psychiatry Psychiatr Epidemiol 43:140-150

26. Hawton K, Bergen H, Casey D, Simkin S, Palmer B, Cooper J, Kapur N, Horrocks J, House A, Lilley R, Noble R, Owens D (2007) Self-harm in England: a tale of three cities. Soc Psychiatry Psychiatr Epidemiol 42:513-521

27. Hawton K, van Heeringen K (2009) Suicide. Lancet 373:13721381

28. Hirsch JK (2006) A review of the literature on rural suicide: risk and protective factors, incidence, and prevention. Crisis 27:189-199

29. Hunt K, Sweeting H, Keoghan M, Platt S (2006) Sex, gender role orientation, gender role attitudes and suicidal thoughts in three generations. Soc Psychiatry Psychiatr Epidemiol 41:641-647

30. Kachur SP, Potter LB, James SP, Powell KE (1995) Suicide in the United States 1980-1992. Centers for Disease Control and Prevention, Atlanta 
31. Kalediene R, Starkuviene S, Petrauskiene J (2006) Seasonal patterns of suicides over the period of socio-economic transition in Lithuania. BMC Pub Health 6:40

32. Kapusta ND, Zorman A, Etzersdorfer A, Ponocny-Seliger E, JandlJager E, Sonneck G (2008) Rural-urban differences in Austrian suicides. Soc Psychiatry Psychiatr Epidemiol 43:311-318

33. Kevan SM (1980) Perspectives on season of suicide: a review. Soc Sci Med 14:369-378

34. Kirkhoff JFM (2000) Attempted suicide: patterns and trends. In: Hawton K, van Heeringen K (eds) The international handbook of suicide and attempted suicide. Wiley, Chichester, pp 49-64

35. Kok LP, Tsoi WF (1993) Season, climate and suicide in Singapore. Med Sci Law 33:247-252

36. Kposowa AJ (2000) Marital status and suicide in the National Longitudinal Mortality Study. J Epidemiol Commun Health $54: 254-261$

37. Kposowa AJ, Bideshi D (2006) Reassessing the sources of racial and ethnic disparities in U.S. adult mortality. West J Black Stud 30:1-14

38. Kposowa AJ (2009) Psychiatrist availability, social disintegration and suicide deaths in U.S. counties, 1990-1995. J Commun Psychol 37(7):3-87

39. Kposowa AJ, Adams M (1998) Automobile crash fatalities in the United States: the effect of race and marital status. Appl Behav Sci Rev 6:69-91

40. Kung HC, Liu X, Juon HS (1998) Risk factors for suicide in Caucasians and in African Americans: a matched case-control study. Soc Psychiatry Psychiatr Epidemiol 33:155-161

41. Lambert G, Reid C, Kaye D, Jennings G, Esler M (2003) Increased suicide rate in the middle aged and its association with hours of sunlight. Am J Psychiatry 160:793-795

42. Lamp R (1983) Time of year and criminality. Paper Presented at the Ninth International Congress of Criminology, Vienna, September

43. Landau SF, Fridman D (1993) The seasonality of violent crime: the case of robbery and homicide in Israel. J Res Crime Delinquency 30:163-191

44. Lee HC, Lin HC, Tsai SY, Li CY, Chen CC, Huang CC (2006) J Affect Disord 92:221-226

45. Lester D, Frank ML (1988) Sex differences in the seasonal distribution of suicides. Br J Psychiatry 153:115-117

46. Lester D (1991) The climate of urban areas in the United States and their rates of personal violence. Death Stud 15:611-616

47. Lieber AL, Sherin CR (1992) Homicide and the lunar cycles: towards a theory of lunar influence on human emotional disturbance. Am J Psychiatry 129:1-4

48. Lönnquist JK (2000) Psychiatric aspects of suicidal behaviour. In: Hawton K, van Heeringen K (eds) International handbook of suicide and attempted suicide. Wiley, New York, pp 107-120

49. Maldonado G, Kraus JF (1991) Variation in suicide occurrence by time of day, day of week, month and lunar phase. Suicide Life Threat Behav 21:174-188

50. MacMahon K (1983) Short-term temporal cycles in frequency of suicide, United States 1972-1978. Am J Epidemiol 117:744-750

51. Massing W, Angermeyer MC (1985) The monthly and weekly distribution of suicide. Soc Sci Med 21:433-441

52. McCleary R, Chew KS, Hellsten JJ, Flynn-Bransford M (1991) Age-and sex-specific cycles in United States suicides, 19731985. Am J Public Health 81:1494-1497

53. Meares R, Mendelsohn FA, Milgrom-Friedman J (1981) A sex difference in the seasonal variation of suicide rate: a single cycle for men, two cycles for women. Br J Psychiatry 138:321-325

54. McIntosh JL, Lester D (2003) The temporal distribution of black suicides. Psychol Rep 93(3):648

55. Morselli J (1881) Suicide: an essay on comparative moral statistics. Kegan Paul, London
56. National Center for Health Statistics. (2008). Multiple Cause of Death Files, 2000-2004. Available at http://www.cdc.gov/nchs. Accessed 1 March 2008

57. Nejar KA, Benseñor IM, Lotufo PA (2007) Sunshine and suicide at the tropic of Capricorn, São Paulo, Brazil, 1996-2004. Revista de saúde pública 41(6):1062-1064

58. Oravecz R, Rocchi MB, Sisti D, Zorko M, Marusic A, Preti A (2006) Changes in the seasonality of suicides over time in Slovenia, 1971 to 2002. J Affect Disord 95:135-140

59. Page L, Hajat S, Kovats RS (2007) Relationships between daily suicide counts and temperature in England and Wales. Br $\mathbf{J}$ Psychiatry 191:106-112

60. Petridou E, Papadopoulos FC, Frangakis CE, Skalkidou A, Trichopoulos D (2002) A role of sunshine in the triggering of suicide. Epidemiology 13:106-109

61. Pubmed (2008) http://www.ncbi.nlm.nih.gov/PubMed. National Library of Medicine, Washington, DC

62. Preti A, Lentini G, Maugeri M (2007) Global warming possibly linked to an enhanced risk of suicide: data from Italy, 1974-2003. J Affect Disord 102(1-3):19-25

63. Qin P (2005) Suicide risk in relation to level of urbanicity: a population-based linkage study. Int J Epidemiol 34:846-852

64. Quetelet A (1842/1968) A treatise on man and the development of his faculties. Burt Franklin, New York

65. Rasanen P, Hakko H, Jokelainen J, Tiihonen J (2002) Seasonal variation in specific methods of suicide: a national register study of 20, 234 Finnish people. J Affect Disord 71:51-59

66. Raudenbush SW, Bryk AS (2002) Hierarchical linear models: applications and data analysis methods. Sage Publications, Thousand Oaks

67. Rogers RG, Hummer RA, Nam CB (2000) Living and dying in the USA. Academic Press, New York

68. Rotton J (1986) Determinism and redux: climate and cultural correlates of violence. Environ Behav 18:346-368

69. SAS Institute (2008) SAS/STATS: the GLIMMIX procedure [computer software]. SAS Institute, Inc., Cary

70. Shi L, Macinko J, Starfield B, Politzer R, Wulu J, Xu J (2005) Primary care, social inequalities, and all-cause, heart disease, and cancer mortality in US counties, 1990. Am J Pub Health 95:674-680

71. Simkin S, Hawton K, Yip PS, Yam CH (2003) Seasonality in suicide: a study of farming suicides in England and Wales. Crisis 24(3):93-97

72. Sociological Abstracts (2008) http://www.csa.com. Cambridge Scientific Abstracts, Bethesda

73. Souetre E, Wehr TA, Douillet P, Darcourt G (1990) Influence of environmental factors on suicidal behavior. Psychiatry Res 32:253-263

74. Stack S (1995) Temporal disappointment, homicide and suicide: an analysis of nonwhites and whites. Sociol Focus 28:313-328

75. Stack S, Kposowa AJ (2008) The association of suicide rates with individual-level suicide attitudes: a cross-national analysis. Soc Sci Q 89:39-59

76. Sutherland EH, Cressey DR, Luckenbill DF (1992) Principles of criminology. General Hall, New York

77. Van Tubergen F, te Grotenhuis M, Ultee W (2005) Denomination, religious context, and suicide: neo-Durkheimian multilevel explanations tested with individual and contextual data. Am J Sociol 111:797-823

78. Wechsberg J (1972) A reporter at large: Mørketiden. New Yorker 48:103-126

79. World Health Organization (2005) International statistical classification of diseases and health related problems (The) ICD-10, 2nd edn. World Health Organization, Geneva

80. Yip PS, Chao A, Chiu CW (2000) Seasonal variation in suicides: diminished or vanished. Experience from England and Wales, 1982-1996. Br J Psychiatry 177(36):6-369 